\title{
Online Learning during COVID-19 Pandemic in Rwanda: Experience of Postgraduate Students on Language of Instruction, Mathematics and Science Education
}

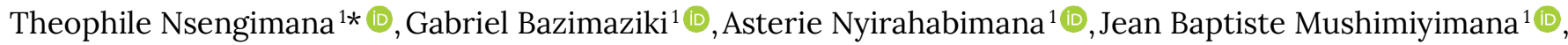



${ }^{1}$ University of Rwanda, College of Education, RWANDA

*Corresponding Author: nsengimanafr@gmail.com

Citation: Nsengimana, T., Bazimaziki, G., Nyirahabimana, A., Mushimiyimana, J. B., Mutarutinya, V., Mugabo, L. R., \& Nsengimana, V. (2021). Online Learning during COVID-19 Pandemic in Rwanda: Experience of Postgraduate Students on Language of Instruction, Mathematics and Science Education. Contemporary Mathematics and Science Education, 2(1), ep21009. https://doi.org/10.30935/conmaths/10788

\begin{abstract}
The COVID-19 pandemic has affected human life at different levels and is still a tremendous challenge for all sectors of life without exception to education. To cope with those COVID-19 effects in education, online teaching and learning was adopted. This study throws light on online learning situation in higher education in Rwanda. The study is geared by interpretivist approach. Data were collected in a series of online individual interviews and focus group discussions with twenty master students from different subjects offered by the African Centre of Excellence for Innovative Teaching and Learning Mathematics and Science (ACEITLMS). The gathered data were analysed thematically. The study revealed communication platforms, ICT infrastructures and software, and online resources as opportunities for online learning. Despite learners' willingness to play their part in online learning, the study further brought to light numerous challenges of learning mathematics and science such as absence of practical activities, inadequate support for structured exercises, few open resources and inadequate access to online resources. Limited internet connectivity, English proficiency coupled with insufficient collaboration among students and with facilitators were reported as limitation too. Since online mode of instruction was adopted for effective blended learning, its adjustment and adaptation are needed to grab the identified opportunities and cautiously address the identified challenges.
\end{abstract}

Keywords: English, mathematics and science education, online teaching and learning, postgraduate students experience

Received: 2 Nov. $2020 \bullet$ Accepted: 22 Dec. 2020

\section{INTRODUCTION}

Mathematics, science, and technology are basic hinges for people to develop, particularly in the current world geared by Information Communication and Technology (ICT). Further, English language as a medium of instruction is acknowledged. Like any other developing country, Rwanda is striving to build a knowledge-based society driven by science and technology at the heart of economic development while English is serving as a medium of instruction in education system in the aftermath of 1994 genocide. While efforts made so far yielded important achievements in the implementation of these policies, COVID-19 has bottled down the speed of the progress in many sectors of human life including education, oftentimes considered as an engine of a country's development.

Originally, the outbreak of pneumonia associated with a novel coronavirus, severe acute respiratory syndrome (SARS) coronavirus 2, was reported in Wuhan, Hubei Province, China, in December 2019. In the weeks that followed, infections spread across China and other countries around the world and on January 30, 2020, the World Health Organization (WHO) declared the outbreak of a Public Health Emergency of International Concern. Later, on February 12, 2020, the WHO named the disease caused by the novel coronavirus "coronavirus disease 2019 - COVID-19" (Zu et al., 2020).

The spread of this pandemic has affected people in the spheres of life because the governments had temporarily closed various services including schools so as to control the spread of the disease. For students, it has had a great impact on ways of learning since classes stopped and they started learning from homes. Teachers were also supposed to switch the teaching and learning methods; and they practise new ways of communication, where much of the learning should be done online through radios, TV channels, different teaching platforms and apps. Parents also have been forced, by the pandemic situation, to act as key teachers of their children. This brought many challenges because not all parents are equipped enough to act as teachers. However, some parents 
with technological skills and means have tried their level best to support their children to learn.

Actually, the closure of millions of schools has led to an emergent distance teaching and learning in higher education as well. Such mode of delivery is not only an opportunity for the generations who are familiar with ICT gadgets but also might be associated with a number of challenges that need be explored in this study. Due to the pandemic that is still rampant, the need to improve online and distance learning has increased in tandem with students need to continue learning while respecting prevention measures. UNESCO (2020) confirmed that many countries have resorted to the use of television and/or radio-based programs to implement distance learning where "Africa seems to be the most active in the efforts to leverage either TV or radio (70\%) while Europe and North America seems to be using less radio than other regions, yet very active in deploying TV-based distance education programmes."

A number of challenges associated with the use of radio and television were identified and they include but without limitation to the non-availability of educational content in audio-visual formats, difficulties of countries to produce content in quantity and quality in short time, the absence of pre-existing partnerships for the design and broadcasting of the educational content, the need for communication and collaboration between education specialists and the professionals of the audio-visual sector for the production of educational programmes. These are added to the lack of the knowhow and expertise in monitoring and evaluation of learning (UNESCO, 2020).

Be that as it may, all the deployed efforts really helped students to learn in a way that they get updated knowledge and get familiar with technological gadgets like telephone, smart phones, tablets, computers, television, radio receptor... but on the other hand, mathematics and science students studying in English - which is not their first nor second language but simply the language of instruction, do not effectively benefit from learning as they expected, only that mathematics and science teaching and learning require various practical activities, demonstrations and lab activities as well as vivid English language interactions that seem difficult to be done online.

Against this background, the present study intends to explore the opportunities and challenges encountered in online learning during COVID-19 pandemic and discusses what can be done for effective learning of mathematics and science via online learning using English as the medium of instruction.

\section{Problem Statement}

Prior to COVID-19, the teaching and learning mathematics and science was reported to be difficult particularly in sub-Saharan African countries. The most reported challenges include fear of failure and inappropriate performance of mathematics and science subjects, limited understanding of mathematic concepts, insufficient resources and inadequate time allocated for practical works, limited time for doing structured exercises caused by heavy workload. These are added to inadequate mastery of the content, mainly for teachers and the methodology used in teaching and learning. Further, both teachers and learners were struggling with English language proficiency improvement to facilitate the teaching and learning process. This is because mathematics and science are taught and learnt in foreign languages. These challenges might have drastically aggravated with the outbreak of COVID-19 where in high education, many modules were shifted to online learning mode.

Challenges with learning mathematics and science online might be rooted in the lack of hands on activities, conducting practical experiments, and doing field trips, while these are core activities to effectively learn mathematics and science, especially for postgraduate students who need to master the subjects both theoretically and practically (Yassamine, 2020). Conversely, learning science online for a master's student would be an advantage to enhance the English language proficiency through skills development in reading, writing, and through discussion forums planned at the learning platforms. Thus, if the current situation of teaching and learning mathematics and science in higher education is explored, it will serve for reference whenever similar or related pandemic occurs.

\section{Purpose of the Study}

The overarching aim of this study was to explore the experience of postgraduate students on online teaching and learning during COVID19 pandemic. With focus on online delivery mode of mathematics and science as well as English as medium of instruction in Rwanda, the research team wanted to explore the situation of online learning by identifying challenges and opportunities of online teaching and learning mathematics and science in higher education in Rwanda. The study was guided by four main research questions:

1. How has COVID -19 pandemic affected the teaching and learning of mathematics and science in the postgraduate programme?

2. What is the implication of language in online learning?

3. What are the opportunities of online learning-teaching in Rwandan high learning education?

4. What are challenges associated with online learning-teaching of mathematics and science?

\section{Scope and Relevance of the Study}

This study examined the situation of online learning and teaching solely adopted by high learning institutions as a consequence of the COVID - 19 pandemic. Particular interest was directed to opportunities and challenges in learning science and mathematics via online mode using English as a medium of instruction for postgraduate students in College of Education of University of Rwanda. The time scope of the study was a period of four months during which students had been learning from home as a result of the COVID-19 pandemic.

\section{LITERATURE REVIEW}

COVID -19 is a pandemic that has spread rapidly and has reached in all parts of the globe. On 31 December 2019, the Wuhan City Health Committee (2019) reported a cluster of 27 pneumonia cases stemming from an unknown etiology, with a preliminary source linking this to the previously closed Wuhan Huanan Seafood Wholesale Market. This was later determined to be a novel coronavirus (2019-nCoV). The Coronavirus 2019 (COVID-19) pandemic has had such an extensive impact on the global higher education sector (Crawford et al., 2020). The pandemic tremendously affected numerous sectors and is still a challenge in many domains worldwide. Education is no exception whereby in higher education face to face teaching and learning left room to online since March 2020 globally. Allen et al. (2020) report that 
online pedagogies serve the interests of teachers and learners and enable the high levels of student engagement and outcomes to which teachers and teacher educators aspire. In this vein, this section explores the opportunities and challenges in the online teaching and learning of science and mathematics subjects using English as a tool of instruction in higher education.

\section{English Medium of Instruction in Science and Mathematics Education}

A medium of instruction is not only a tool to teach and learn the subject content but also a means to be proficient in that language especially when it is not learners' L1. As mathematics and science are adopted and developed as new standards for English language acquisition, it is acknowledged that content areas are important arenas for the development of both academic language and language skills for everyday communication (IFI, 2015). For a student doing a Master of Education in mathematics and science, the intended learning outcomes should not leave out the room for language enhancement so that they can feel more conversant with it not only in the workplaces after they complete studies but also in their research activity. Hence, language integration in science learning imposes an important space in higher education in particular.

Students who learn their courses in English as their second language are expected to develop it through the subjects they take particularly because they are trained to be educators and researchers in science and mathematics education or the like. In both cases, they will need to be fluent in English for effective communication at the workplace or in other similar situations; because English has become not only a dominant medium of instruction, but also an equaled language in this era driven by science and technology. Among the identified drivers at the heart of the rapid growing of EMI in higher education worldwide, Macaro et al. (2019) emphasized students' English proficiency and using it as "a neutral language" in contexts where the national language(s) is/are in dispute. This implies that science and mathematics students at tertiary level are no exception in Rwanda, in particular, where English is used as a second language.

Be that as it may, following the IFI (2015) report, the direct and engaging experiences of inquiry-based science offers a rich context for language development, and in the same vein, the use of language to communicate ideas is essential to the development of scientific understanding. However, it is skeptical whether students learning mathematics and science online will likely improve their language as it should be with face to face where they can have time and space for interaction, discussion, comments on the results from laboratory works, among other things; or whether learning mathematics and science online offers more opportunities to improve English as a second language. It is against this perspectivism that this study was deemed worthwhile with reference to education in Rwanda during the period of COVID-19 pandemic.

\section{Language Enhancement through Online Learning: Opportunities and Challenges}

Online learning resources are now beginning to be taken more seriously and are even becoming compulsory in certain institutions ( $\mathrm{Li}$ et al., 2020). Most of the universities-university of Rwanda includedcreated videos and teaching guides and conducted online workshops to equip staff and students to use various online learning platforms (e.g., Microsoft Teams, Zoom, Moodle, and Google Drive). The content of the training was based on the request from lecturers and developed by the information technology team of the universities, to ensure different stakeholders are competent and familiar with the relevant skills of online teaching and learning. Later, universities developed synchronous and asynchronous online learning approaches (Crawford et al., 2020).

On the one hand, in universities where English is adopted as a medium of instruction- the chance for English language learning and mastery increased since there were accompanied by facial expressions, gestures or any other body language or even a mixture of mother tongue to explain the content to students. Lectures and students have to be courageous enough to use and learn all possible lexicons and structures to teach and learn the program materials.

New lexicon and structures can be learned while teaching other program materials. According to Lisa et al. (2020), English language is being enhanced through social media use, people interacting on the COVID-19 pandemic issue that has become today a mundane problem. Among other things, discussions among people center on the situation as regard the pandemic, spreading, how it is mining thousands of people and measures and strategies put forward to grapple with it. In that line, the pandemic has become a source of English language exposition, advertisement and improvement. It goes without saying that everyone being academicians, higher learning students, businessmen and women, politicians, etc were very keen, curious and even afraid to know what is happening as the pandemic concerns all people's lives. New lexicons like pandemic, lockdown, outbreak, coronavirus, confirmed cases, quarantine, spread, face mask, novel, and confinement among others have been learned worldwide as a result of COVID-19 era. However, the related learning and information communication technologies may have been a challenge or an opportunity to learn English language.

On the other hand, Atmojo et al. (2020) discussed some challenges to teaching and learning English language and reported that those challenges include technology related pedagogies, designing interactive activities, enhancing formal learning, gaining students' support, and dealing with problems in the use of technology. Other difficulties in fully online learning are meeting scheduled participation and regular learning, maintaining persistent engagement, becoming a self-directed learner with high motivation, and socializing. Problems also come from the inability to afford smartphone and internet quota for students as well as the unstable internet connection. Henceforth, good pedagogy will be nonsense if there are problems in technology access. The two authors conclude that preparing online learning takes more time and needs a bigger investment than preparing face-to-face class.

In Rwanda, University of Rwanda- with its six colleges respectively- closed the doors between 16 March 2020 and $2^{\text {nd }}$ November 2020. During this period, students as well as lectures were asked to teach and learn from home through the University e-learning platform which is Moodle. Though University of Rwanda envisages a blended learning mode since 2015, not all lecturers and students are well conversant with technology related skills that are imperative for online learning. Despite that full access to the learning platform is guaranteed, the problem of lack of ICT gadgets coupled with lack or slow internet connectivity, students' intrinsic motivation, self-learning engagement and management, high level of English proficiency, all are still a serious impediment to successful online learning. 


\section{ONLINE LEARNING MATHEMATICS AND SCIENCE: OPPORTUNITIES AND CHALLENGES}

To respond to the COVID-19 pandemic challenges in learning, many universities are adapting and introducing educational technology products, like the video-conferencing platforms such as Zoom and Moodle to continue learning. In most cases, these technologies existed but not fully exploited (Czerniewicz, 2020). However, the question is still whether online teaching will spell a return to more traditional ways of teaching, and what consequences might be, in terms of both teachers' and students' engagement (Allen et al., 2020).

While Yakin et al. (2020) found out that E-learning is rendered ineffective by challenges such as unavailability of digital equipment, skills, internet and related resources. In the same line, Bazimaziki (2020) reports that the situation exacerbates for some students living in rural areas without internet and electricity facilities. However, for postgraduate students doing Science and Mathematics with Education, online learning should be a ground to maximize related opportunities despite challenges they have to grapple with for each. On one hand, they can make it an opportunity to improve English language proficiency since it is a medium of instruction. They can also have enough time for doing research as they manage themselves despite teachers' remote support. On the other side, there are activities that will be sacrificed like laboratory, practical activities, hands on which affect mastery of the content and learning outcomes as well. Taken all in all, although online has been a possible solution where face to face was impossible especially during the COVID-19 lockdowns, research reveals numerous challenges going against it.

Hollweck et al. (2020) noted that despite significant challenges for educators, policymakers, school leaders, students and families, the COVID-19 pandemic is a critical opportunity to rethink the future of schooling. The authors suggested transformational change for schools and school systems focusing on their professional capital collaboration with the larger school community. Similarly, Bentata (2020) opines that the COVID-19 is an opportunity which she termed a "true apprenticeship" in that it has obliged the whole world to use technological tools to ensure teleworking forcing institutions and countries to invest in distance education and fully adapt to it very rapidly. However, the same author posits that the pandemic has brought more challenges than opportunities with distance learning since most of the countries concerned were not prepared for such an unprecedented situation. In line with all the literature reviewed, related studies conducted on post graduate programmes are still needed to bridge some gaps. This is the reason that triggered the researchers to investigate the situation in Rwanda higher education with specific interest in post graduate programmes students doing mathematics and science with education to bridge the gap.

\section{METHODOLOGY}

The study adopted a qualitative research approach through interpretivism design. Qualitative data were collected from 20 Master's programme students pursuing Master of Education in Biology, Chemistry, Physics, and Master of Mathematics Education. Both female and male participants had basic ICT skills and were selected purposely as they were studying online during COVID-19 pandemic. Information was gathered through seven main questions sent to individual students' emails and recording online group discussions through webex for few of selected students. The questions to be answered were designed for both individuals and group discussions to reveal the current situation of online learning with emphasis on what is done in online learning, opportunities - challenges for online learning and the prospective needful strategies. The recorded data were transcribed then analysed qualitatively through content analysis.

\section{FINDINGS}

\section{COVID-19 Effects on the Teaching and Learning of Mathematics} and Science Education

Because of the COVID-19 pandemic, the teaching and learning of mathematics and science education has changed as students could not meet their lecturers in compliance with the measures to fight the spread of that pandemic. For some students, online learning was challenging as they were in remote areas where they could not have direct access to electricity and also to the internet. This caused them even not to regularly attend the planned online lessons. Further, practical works or simulations which are the foundation for deep understanding of scientific concepts were not performed.

Beside practical works, participants confirmed to have received many online exercises to work on. Some of them were without clear instructions to follow. Even though the online learning emphasizes chats and discussions, a limited knowledge sharing and construction through collaborative learning on the structured exercises was reported. Such practices were attributed to leaving some misconceptions amongst students. Another issue experienced by postgraduate students pertains to the limited number of resources as there is no surrounding library to supplement the online resources provided by the facilitators. They were to rely on the provided resources since other online resources which are not given by their facilitators are costly and difficult to access.

Online assessment was perceived not to allow students to achieve higher compared to the normal face to face mode of learning. Depending on the type of assessment activities, feedback is either immediately provided like in case of ICT integration in education or takes some days to get it. Participants reported that there are no mathematics and science practical skills developed as they were not performing hands-on activities. They simply acquire superficial knowledge as they don't work together. This cooperative learning was perceived as the effective way to foster deep understanding and high performance. Further, findings indicated that with online learning participants developed skills in the use of technology, got the ability to solve related technical challenges, improved communication, listening, critical thinking and research skills among others.

\section{Opportunities}

The University of Rwanda, College of Education has embarked on online teaching and learning some days prior the rise and spread of COVID-19. With this new way of teaching and learning, infrastructure for ICT technologies and software were in place. Further, materials for online teaching and learning were previously developed and uploaded online. Lecturers were trained on the use of educational technology too.. Another opportunity was that all postgraduate students had computers and financial facilities that could be used in online learning. 
Furthermore, lecturers and students were able to use English as medium instruction, readiness of competent lecturers used in facilitating the learning, and students' willingness in taking part in forums and chat discussions was also in place.

In relation with English as a medium of instruction, findings of this study revealed that there was no special problem with English as a medium of instruction as one said "no challenges related to the use of medium language of instructional" [sic] while some others reveal that they did not have enough room to improve their language through discussion ".... only forum discussion and chats are possible and English is not mother tongue so using is alone is not good at all, .... [sic] while another claims that there was " lack of effective collaboration with classmates”. Actually, when learners interact during online learning, they not only take advantage of mutual exchange on the lesson but also grab an opportunity to enhance their communication skills in that language. To illustrate, one of the participants put it well that "Some teachers used discussion forum and chats, this was really good but the way it was done it was like posting and some facilitators do not oblige us to reflect to other classmates post which I found somehow motivating to read others post hence to improve skills of communication, listening, critical thing, valuing and so on" [sic] an idea emphasized in another participants words that "Discussion and chat was done at appreciable level though further explanation was missing and use of English can be extended than usual."

\section{Challenges}

A number of challenges are identified by participants such as lack of access to physical laboratories, virtual laboratories and field trips, poor connection and limited skills on computer and technical problems, working alone on structured exercises instead of collaborating with colleagues was not enough to understand concepts, inadequate collaboration between lecturers and students and between students, limited knowledge and skills on ICT tools and software e.g. Geogebra, ChemDraw, etc. enable students to do well on structured exercises, limited access to reading material and no access to important resources from online libraries due to lack of subscription. Only one attempt on multiple choices questions allowed during tests and quizzes was also noticed as challenge and feedback is not conveyed in effective ways as they received written comments with no further suggestions for improvement. Lower levels of knowledge are assessed and acquired among students and performance is poor generally because of distractions that are in the individual learning environment. Another identified and reported challenge is that some lectures are not conversant with educational technologies.

\section{DISCUSSIONS}

Due to COVID-19 pandemic, online learning has been imperative for the postgraduate programme of ACEITLMS as there was no other option. Taking into consideration the existing opportunities for this new way of learning, studies of postgraduate students have been affected since they were not very familiar with it and of course, following Benlounissi (2020), the virtual presence cannot replace the physical presence of the teacher or the student because this presence would have created the human bonds which these students needed to feel confident in order to build their knowledge more successfully.
Considering information revealed by this study to enable online learning, it has been reported that opportunities were not fully grabbed due to inadequate preparedness. Having some ICT gadgets was reported as an advantage, however, students and majority of lecturers were using them for their personal reporting and research but not yet for teaching and so called online learning. From this study, online learning was appreciated in one course of ICT integration in education whereby the activities planned and facilitation done were appreciated by the students. In other courses, particularly those of subject specific i.e., biology, chemistry, physics and mathematics; online learning was seen as a platform from which exercises and reading materials are readily available.

Despite the availability of learning resources and activities, the quality of some activities and resources were not clear, hence learning was affected. Further, some students were having difficulties to access them and for some it was not easy to understand not easily understand what they are all about. To make ICT gadgets fully used in teaching and learning and having well prepared resources, there is a need for students and teachers to master those new technologies. In particular, lecturers as facilitators of the learning need to be equipped with appropriate skills to enable effective and productive interactions among students and with their lecturers.

While online learning involves the teacher and the student either to work together and interact at an arranged time - that is synchronous form, or students working alone without the intervention of the teacher, asynchronous in that case (Cahapay, 2020), some subjects like mathematics and science dictate the use of synchronous form particularly for the sake of practice. In this tandem, other challenges specific to the nature of the subjects being facilitated via online learning were identified in this study. Among them, lack of practical activities specific to science comes first. Since science is about exploration or investigation of the phenomena for understanding of concepts, the practical works is imperative. As the COVID-19 pandemic prevents students from going to laboratories to carry out investigations, one of the alternatives to support learning is through virtual experiments. In this regard, the free online virtual experiments available could have been suggested. However, virtual activities may also be missing depending on the nature of the topic, therefore, when the COVID-19 situation may be alleviated, there is a need to expose students to such practical activities. From this situation, it is important to emphasize the role of physical presence of both teachers and students in teaching and learning mathematics and science; which is an invaluable factor for effective lesson delivery.

As a matter of fact, learning mathematics and science online affects negatively students' interactions besides teacher's difficulties to control the learners' behaviours. Benlounissi (2020) put it that the great impact of online learning during a pandemic is that the virtual presence of teachers or students cannot replace their physical presence since the latter would have created the human bonds which students needed to feel confident in order to build their knowledge. More specifically, in virtual learning practical works are jeopardized as well reported by one participant saying " no practical work was conducted" a point raised by another participant at large "As someone who are doing science and you know that there many practical works required for sure this pandemic period affected us as we are learning online hence no practical has been done as we did not access on the laboratory and also we did not use any ICT resources like simulation to replace normal laboratory (in order to 
conduct the practical) to overcome that challenge"[sic]. Be that as it may, students learning mathematics and science fully online are disadvantaged in the light of practical works and experiments as well. This said, science learning without experiments, particularly for master's students being trained to be teachers, will bear serious consequences related with subject teaching at the workplaces. It will also affect them when they are assigned tasks or exposed to relate practical works be in their academic or research based tasks. Besides the practical experiments specific to science, the structured number of exercises given to students in all studies modules could also be relevant for students as they were busy doing them. Definitely, there is a need to create and improve the way students should collaborate in doing exercises since many students realised that they didn't perform them correctly which might result in inadequate performance as some quote “...because of a limited knowledge sharing which is not well done as there is no effective collaboration, there is tendency of poor performance". To improve collaboration, through online learning platforms, lecturers could make groups or sub panels in which students can be in small rooms working on the assigned tasks. After the group or sub panels discussions, ideas from different groups should be shared in a whole group. With discussions and collaboration, students would enhance their English proficiency which was not good for some mainly because many of them use it as a second language.

Inherently, while social interaction using English appeared to be a successful way forward for developing the language, enhancing communicative competence (Hudson, 2009), it is at disadvantage of mathematics and science learners when they don't have opportunity to discuss using English as a medium of instruction (EMI) especially in a case they are non- native speakers of English. Once English proficiency is bolstered, deep understanding of the concepts via the reading of uploaded material is feasible. Form the above participants' situation, it is important to confirm that English as a medium of instruction (EMI) holds a vital part in online learning mathematics and science. It is clear that some students took advantage of it as they did not face language challenge while some others were disadvantaged particularly in as much as they did not enhance their language proficiency as expected. From what they revealed, their expectation was not only mathematics and science skills, but also language enhancement through activities such as forum discussion and live chart during the course.

The poor quality learning was also attributed to the multiple choice assessment where some students may fail not because they don't understand the module but due to mono-assessment type. In this regard, varying assessment techniques could serve as a solution since students learn differently, they should be also assessed in different ways. Further, monitoring of students to identify who participate and who don't is important. Therefore, a monitoring instrument and technique should be developed.

As some lecturers have not yet willingly embraced this online mode, which in some instances prevents them from planning and adequately supporting students for effective learning, there is a need for them to be committed and change their perceptions towards the $21^{\text {st }}$ century education which hinges on and is geared by ICT.

\section{CONCLUSIONS AND RECOMMENDATIONS}

This study was conducted to explore online learning during COVID-19 pandemic in Rwanda with particular interest in experience of postgraduate students on language of instruction in mathematics and science education. While mathematics, science and technology are basic hinges for people to develop particularly in the current world geared by Information Communication and Technology, the results showed that fully online learning mathematics and science has more disadvantages than advantages. The way it was conducted must be improved and evolve in favour of the beneficiaries.

Taken all in all, based on what other research revealed, Cahapay (2020) for example, the transition to E-learning from face to face has been successful while gained experience can serve for reference in favour of future generations. Since the online mode of instruction was adopted to support face to face mode, in future, based on the experience with COVID-19 pandemic, the reported opportunities should be grabbed while cautiously addressing the identified challenges to improve online learning. Challenges related with lab activities and field trips in mathematics and science education are to be given much consideration whatever mode of delivery is used. Particularly, lecturers should consider that online learning mathematics and science augurs not only content mastery but also language enhancement, scientific language in particular. So, they should not undermine students' forum posts and chat live room by giving constructive feedback rather than encouraging learners to be passive without engaging them. Further, the training on the facilitation using online features is recommended for both students and lecturers for effective online teaching and learning. By and large, for online education to be effective during a pandemic like COVID-19, none of the responsible parts could undermine their roles each as concluded in Arroio (2020) that remote teaching and learning during a pandemic requires mutual support and knowledge of the reality and the feeling of others so as to help them because without mutual help, it does not seem possible to deal with uncertain times.

Author contributions: All authors were involved in concept, design, collection of data, interpretation, writing, and critically revising the article. All authors approve final version of the article.

Funding: The authors received no financial support for the research and/or authorship of this article.

Declaration of interest: Authors declare no competing interest.

Data availability: Data generated or analysed during this study are available from the authors on request.

\section{REFERENCES}

Adedoyin, O. B., \& Soykan, E. (2020). Covid-19 pandemic and online learning: the challenges and opportunities. Interactive Learning Environments. Published online: 2 September 2020. https://doi.org/10.1080/10494820.2020.1813180

Allen, J., Rowan, L., \& Singh, P. (2020) Teaching and teacher education in the time of COVID-19. Asia-Pacific Journal of Teacher Education, 48(3), 233-236. https://doi.org/10.1080/1359866X.2020.1752051

Arroio, A. (2020). The Value of Education In The Context Of Covid19 Pandemic. Problems of Education in the 21st Century, 78(3), 309. https://doi.org/10.33225/pec/20.78.309

Atmojo, A. E. P., \& Nugroho, A. (2020). EFL Classes Must Go Online! Teaching Activities and Challenges during COVID-19 Pandemic in Indonesia. Register Journal, 13(1), 49-76. https://doi.org/10.18326/ rgt.v13i1.49-76 
Bazimaziki, G. (2020). Challenges in using ICT Gadgets to cope with effects of COVID-19 on Education: A short survey of online teaching Literature in English. Journal of Humanities and Education Development (JHED), 2(4), 299-307. https://doi.org/10.22161/ jhed.2.4.8

Benlounissi, A. (2020). Impact of learning, exclusively online, during a pandemic. Journal of Humanities and Education Development (JHED), 2(6), 385-389. https://doi.org/10.22161/jhed.2.6.1

Bentata, Y. (2020). COVID 2019 pandemic: a true digital revolution and birth of a new educational era, or an ephemeral phenomenon? Medical Education Online, 25(1), 1781378. https://doi.org/10.1080/ 10872981.2020.1781378

Cahapay, M. B. (2020). Rethinking education in the new normal postCOVID-19 era: A curriculum studies perspective. Aquademia, 4(2), ep20018. https://doi.org/10.29333/aquademia/8227

Crawford, J., Butler-Henderson, K., Rudolph, J., Glowatz, M., et al (2020). COVID-19: 20 Countries' Higher Education Intra-Period Digital Pedagogy Responses. Journal of Applied Teaching and Learning(JALT), 3(1), 9-28. https://doi.org/10.37074/jalt.2020.3.1.7

Czerniewicz, L. (2020). What we learnt from "going online" during university shutdowns in South Africa. PhilonEdTech. Retrieved from https://philonedtech.com/what-we-learnt-from-goingonline-during-university-shutdowns-in-south-africa

Hollweck, T., \& Doucet, A. (2020). Pracademics in the pandemic: pedagogies and professionalism. Journal of Professional Capital and Community, 5(3/4), 295-305. https://doi.org/10.1108/JPCC-062020-0038

Hudson, P. (2009). Learning to Teach Science Using English as the Medium of Instruction. Eurasia Journal of Mathematics, Science and Technology Education, 5(2), 165-170. https://doi.org/10.12973/ ejmste/75268
Institute for Inquiry (IFI). (2015). Developing Language in the context of Science: A view from Institute for Inquiry. Exploratorium. Retrieved from www.Exploratorium.edu

Li, L., Lin, M., Wang, X., Bao, P., \& Li, Y. (2020). Preparing and responding to 2019 novel coronavirus with simulation and technology-enhanced learning for healthcare professionals: challenges and opportunities in China. BMJ Simulation and Technology Enhanced Learning, 6, 196-198. https://doi.org/10.1136/ bmjstel-2020-000609

Macaro, E., Akincioglu, M., \& Han, S. (2019). English Medium of Instruction in Higher Education: Teacher perspectives on professional development and certification. International Journal of Applied Linguistics, 30(1),1-14. https://doi.org/10.1111/ijal.12272

Singh, L., Bansal S., Bode, L., Budak, C., Chi, G.; Kawintiranon, K., Padden, C., Vanarsdall, R., Emily Vraga, E., \& Wang, Y. (2020). A first look at COVID-19 information and misinformation sharing on Twitter. ArXiv. Preprint. 2020 Mar 31: arXiv:2003.13907v1.

UNESCO (2020). Learning through radio and Television in the time of COVID-19. Retrieved from https://en.unesco.org/news/learningthrough-radio-and-television-time-covid-19

Yekin, N.A., Adigun, J.O., Ojo, O., \& Andakinwole, A. K. (2020). Assessment of Adoption of E - Learning and M- Learning During COVID-19 Lockdown in Nigeria. International Academic Journal of Education and Literature, 1(1), 28-34. Retrieved from https://www.iarconsortium.org/journal-info/IAJEL

Zu, Z. Y., Jiang, M. D., Xu, P. P., Chen, W., Ni, Q. Q., Lu, G. M., Zhang, L. J. (2020). Coronavirus Disease 2019 (COVID-19): A Perspective from China. Radiology, 296(2), E15-E25. https://doi.org/10.1148/ radiol.2020200490 